\title{
EL IMPACTO ECONÓMICO DEL TURISMO EN EL PERÚ 1990 - 2015
}

\author{
THE ECONOMIC IMPACT OF TOURISM IN PERU 1990 - 2015
}

\author{
José Manuel Enrique Marsano Delgado \\ Universidad de San Martín de Porres, Perú
}

Aceptado: 20 de julio de 2016

\section{RESUMEN}

El artículo analiza y evalúa el comportamiento macroeconómico del sector turismo en el Perú entre los años 1990 - 2015, con especial atención en su creciente importancia económica en el sector servicios, así como en sus posibilidades de desarrollo para el período 2016 - 2019. El análisis y la evaluación se basaron en la información cuantitativa del Banco de Datos Turísticos del Perú (Badatur Perú), del Observatorio Turístico del Perú.

Palabras clave: Turismo receptor, turismo interno, gasto, tasa de crecimiento, demanda, oferta.

\begin{abstract}
The article analyzes and evaluates the macroeconomic performance of the tourism sector in Peru between the years 1990 - 2015, with special attention placed in the growing economic importance of its service sector, and its development prospects for the period 2016-2019. The analysis and evaluation are based on quantitative information from the Tourist Data Bank of Peru (Badatur Peru), Tourism Observatory of Peru.
\end{abstract}

Keywords: Inbound tourism, domestic tourism, spending, growth rate, demand, supply

\section{Introducción}

Durante los primeros años de la década de los noventa el desarrollo del turismo mostró indicadores negativos. En efecto, entre 1988 y 1992, el número de turistas extranjeros se redujo de 359.000 a 216.534 visitantes, lo cual representó una tasa media anual de contracción en el turismo receptor de $-11,87 \%$ debido principalmente al clima de violencia terrorista que condujo al país a un estado de inestabilidad económica y social.

El impacto fue muy severo en los ingresos por concepto de divisas, tanto en el ámbito de las cuentas nacionales, como en los ingresos del sector turismo. Es así que los ingresos en el período 1988 - 1992, mostraron una tasa anual de crecimiento negativo del orden del $-11,30 \%$. Es en aquellos años que se aplican en el país un conjunto de medidas orientadas a pacificar el país y estabilizarlo económicamente, lo que mejoró sustancialmente la imagen turística del Perú en el exterior. Ello se evidenció en los ingresos de divisas del 
sector, los mismos que crecieron en el período 1993 - 2012 a una tasa media anual del 15,34\%. Mientras que en el período 1990 - 2015 la tasa de crecimiento media anual fue del 12,52\% (Tabla1).

Tabla 1

Perú: Ingresos monetarios del turismo receptor

\begin{tabular}{cc}
\hline Año & Ingresos en dólares \\
\hline 1990 & 217.000 .000 \\
1991 & 225.000 .000 \\
1992 & 156.000 .000 \\
1993 & 215.000 .000 \\
1994 & 331.000 .000 \\
1995 & 428.000 .000 \\
1996 & 670.000 .000 \\
1997 & 816.000 .000 \\
1998 & 845.000 .000 \\
1999 & 890.000 .000 \\
2000 & 911.000 .000 \\
2001 & 788.000 .000 \\
2002 & 801.000 .000 \\
2003 & 923.000 .000 \\
2004 & 1.142 .000 .000 \\
2005 & 1.308 .000 .000 \\
2006 & 1.383 .000 .000 \\
2007 & 1.854 .000 .000 \\
2008 & 2.380 .000 .000 \\
2009 & 2.015 .000 .000 \\
2010 & 2.242 .472 .508 \\
2011 & 2.695 .000 .000 \\
2012 & 3.240 .000 .000 \\
2013 & 3.514 .000 .000 \\
2014 & 3.621 .394 .882 \\
2015 & 4.139 .610 .050 \\
\hline Tasa de crecimiento anual: $12,52 \%$ \\
Elaboración: Observatorio Turístico del Perú \\
\end{tabular}

Para el período 2016 - 2019, se ha estimado una tasa media anual de crecimiento en los ingresos del turismo receptor peruano del 3,69\%. Teniendo en consideración las secuelas de la crisis económica mundial. Hemos partido de la premisa de que el gasto Per cápita se mantendrá en un monto no mayor a US\$ 1.282 dólares (Tabla 2).

El desenvolvimiento del flujo del turismo receptor, pese a los atentados terroristas del 11 de septiembre del año 2001, mostró un flujo de arribos de visitantes, cuya tasa promedio de crecimiento anual para el período 1993 2012 ha sido del 12,45\% y en el período 1998 - 2015 fue del 8,48\%; en tanto que las estimaciones del Observatorio Turístico del Perú, de la Escuela Profesional de Turismo y Hotelería de la Universidad de San Martín de Porres, para el período 2016 - 2019, señalan que el mismo experimentará una tasa anual esperada 
Tabla 2

Perú: Ingresos monetarios del turismo receptor proyectados

\begin{tabular}{cc}
\hline Año & Ingresos en dólares \\
\hline 2016 & 4.292 .361 .661 \\
2017 & 4.450 .749 .806 \\
2018 & 4.614 .982 .474 \\
2019 & 4.785 .275 .327 \\
\hline
\end{tabular}

Tasa de crecimiento anual: $3,69 \%$

Fuente: BADATUR del OTP

Elaboración: Observatorio Turístico del Perú

de crecimiento del 3,0\%. Consideramos, que no debe de perderse de vista aún los embates económicos mundiales, conforme lo señalamos en el párrafo anterior (Tablas 3 y 4).

Tabla 3

Perú: Turismo receptor histórico 1988-2015

\begin{tabular}{cc}
\hline Año & Turismo receptor cantidad de personas \\
\hline 1988 & 359.000 \\
1989 & 334.000 \\
1990 & 316.871 \\
1991 & 232.012 \\
1992 & 216.534 \\
1993 & 271.901 \\
1994 & 386.120 \\
1995 & 479.231 \\
1996 & 662.736 \\
1997 & 746.599 \\
1998 & 819.530 \\
1999 & 944.000 \\
2000 & 793.183 \\
2001 & 792.466 \\
2002 & 859.379 \\
2003 & 881.010 \\
2004 & 1.244 .608 \\
2005 & 1.296 .010 \\
2006 & 1.347 .850 \\
2007 & 1.540 .107 \\
2008 & 1.822 .358 \\
2009 & 1.754 .528 \\
2010 & 1.949 .976 \\
2011 & 2.242 .472 \\
2012 & 2.528 .373 \\
2013 & 2.742 .526 \\
2014 & 2.824 .801 \\
\hline Elaboración: Observatorio Turístico del Perú & \\
\hline dente: & 3.229 .025 \\
\hline crecimiento: $8,48 \%$ & \\
\hline
\end{tabular}


Tabla 4

Perú: Turismo Receptor Proyectado 2016-2019

\begin{tabular}{cc}
\hline Año & Turismo Receptor Proyectado \\
\hline 2016 & 3.325 .896 \\
2017 & 3.425 .673 \\
2018 & 3.528 .442 \\
2019 & 3.634 .296 \\
\hline Tasa de crecimiento: 3,0\% & \\
Fuente: BADATUR - OTP & \\
Elaboración: Observatorio Turístico del Perú
\end{tabular}

\section{Evaluación del Turismo en el Perú 1990 - 2015}

\section{El turismo receptivo}

De los 3.229.025 visitantes extranjeros no residentes que arribaron el país en el año 2015; el origen de procedencia por continentes fue el siguiente: América 77,69\%; Europa 16,67\%; Asia 4,14\%; Oceanía 1,36\% y África $0,14 \%$ (Tabla 5).

Tabla 5

Turismo receptor peruano por continentes año 2015

\begin{tabular}{lr}
\hline Continente & \multicolumn{1}{c}{ Arribos } \\
\hline América & 2.508 .772 \\
África & 4.420 \\
Asia & 133.765 \\
Europa & 538.314 \\
Oceanía & 43.754 \\
\hline Total Arribos & 3.229 .025 \\
\hline Fuente: OTP - BADATUR - SNM & \\
Elaboración: Observatorio Turístico del Perú &
\end{tabular}

A nivel de países emisores, los más importantes durante el año 2015 fueron: Chile, con una participación del 29,00\% del total de visitas, en segundo lugar se encuentra Estados Unidos con el 15,83\% de visitantes, Ecuador ocupa el tercer lugar con una participación del 7,23\% de visitas, Argentina se ubicó en el cuarto lugar con un 5,02\% del total de arribos. Es decir, cuatro países representan el 57,08\% del turismo receptor peruano y de ellos dos son fronterizos con Perú.

Existe un campo muy amplio para la diversificación del turismo receptor. Los países europeos y casi todos los asiáticos aún no se encuentran entre los principales países emisores y constituyen, por lo tanto, regiones emisoras de turistas de interés, especialmente por el elevado nivel cultural de su población, como por su alto poder adquisitivo (Tabla 6). 
Tabla 6

Los quince primeros países generadores de visitas hacia el Perú

\begin{tabular}{lc}
\hline \multicolumn{1}{c}{ País } & Cantidad de Visitantes 2015 \\
\hline Chile & 936.310 \\
Estados Unidos & 511.279 \\
Ecuador & 233.429 \\
Argentina & 162.158 \\
Colombia & 151.904 \\
Brasil & 142.989 \\
España & 129.185 \\
Bolivia & 112.050 \\
Francia & 84.409 \\
Alemania & 70.292 \\
Mexico & 69.168 \\
Canadá & 64.471 \\
Reino Unido & 60.385 \\
Italia & 55.755 \\
Japón & 53.868 \\
\hline
\end{tabular}

Fuente: BADATUR del OTP, SNM

Elaboración: Observatorio Turístico del Perú

Se sabe también que los turistas que vienen al Perú en mayor proporción, $56 \%$ se encuentran en un rango de edad que fluctúa entre los 25 - 44 años de edad. Una mayor proporción de ellos son hombres $61 \%$ y el $89 \%$ del total tienen educación superior universitaria o estudios de postgrado.

Por otro lado, el $65 \%$ trabajan es sus países de origen a tiempo completo; sus ingresos anuales en un $77 \%$ fluctúan entre los 15.000 y 200.000 dólares. Esto indica que la capacidad de gasto de estos turistas es elevada, lo cual permite inferir que los ingresos no son una restricción en la decisión de viajar.

El arribo de turistas al Perú se realiza durante todo el año, pero en forma significativa en dos estaciones en particular. La primera de ellas ocurre entre los meses de julio - agosto, periodo que coincide con la época de verano y vacaciones en el hemisferio norte, principalmente en los Estados Unidos de Norteamérica, y es precisamente el periodo de mayor salida de nacionales de dicho país hacia otros países. La segunda estación importante es a fines de año [entre diciembre y enero], influenciada principalmente por el periodo de verano y vacaciones en países vecinos como Chile y Ecuador. Desde 1994, cuando empezó el crecimiento sostenido del turismo receptor, la estacionalidad se ha mantenido, aunque no en forma muy significativa. Es posible que las campañas de publicidad se hayan concentrado en promocionar destinos específicos en los períodos antes señalados, lo cual puede ser importante en el corto plazo pero en el mediano plazo puede generar concentración y saturación de la demanda.

En ese sentido, considerando las condiciones climáticas y variada oferta turística, un reto para el mediano y largo plazo debería ser el promover el turismo receptor a nivel de distintos nichos de mercado, como el ecoturismo, el turismo de aventura y otros sumamente refinados, como el de la observación de la fauna y 
flora, en donde contamos con ventajas comparativas. Un ejemplo de lo antes expuesto lo tenemos con el Santuario de Machu Picchu, en el cual la tasa media anual de visitantes a la ciudadela mostró un crecimiento medio anual durante el período 1993 - 2015 del 11,06\%. Habiendo recibido durante el año 2015 la cantidad de 1.282.515 visitantes. Es decir, un promedio diario de 3.514 personas, considerando los 365 días del año (Tabla 7).

\section{Tabla 7}

Llegada de visitantes al Santuario Histórico de Machu Picchu

(Ciudad Inka de Machu Picchu, Camino Inka Piscacucho km 82, Camino Inka Qorywayrachina km 88, Camino Inka Chachabamba km 104)

\begin{tabular}{|c|c|c|c|}
\hline Año & Extranjeros & Nacionales & Total \\
\hline 1980 & 100.534 & 45.032 & 145.566 \\
\hline 1981 & 96.060 & 37.214 & 133.274 \\
\hline 1982 & 77.234 & 46.548 & 123.782 \\
\hline 1983 & 65.570 & 54.552 & 120.122 \\
\hline 1984 & 72.069 & 51.450 & 123.519 \\
\hline 1985 & 67.545 & 59.169 & 126.714 \\
\hline 1986 & 77.966 & 63.686 & 141.652 \\
\hline 1987 & 89.726 & 101.162 & 190.888 \\
\hline 1988 & 116.911 & 70.431 & 187.342 \\
\hline 1989 & 97.594 & 51.842 & 149.436 \\
\hline 1990 & 72.867 & 47.682 & 120.549 \\
\hline 1991 & 41.112 & 36.183 & 77.295 \\
\hline 1992 & 39.724 & 54.851 & 94.575 \\
\hline 1993 & 58.090 & 69.525 & 127.615 \\
\hline 1994 & 111.083 & 96.539 & 207.622 \\
\hline 1995 & 159.590 & 88.951 & 248.541 \\
\hline 1996 & 198.664 & 98.334 & 296.998 \\
\hline 1997 & 189.030 & 105.002 & 294.032 \\
\hline 1998 & 227.709 & 106.854 & 334.563 \\
\hline 1999 & 286.600 & 95.591 & 382.191 \\
\hline 2000 & 352.294 & 68.096 & 420.390 \\
\hline 2001 & 294.437 & 126.433 & 420.870 \\
\hline 2002 & 308.814 & 148.284 & 457.098 \\
\hline 2003 & 333.805 & 190.003 & 523.808 \\
\hline 2004 & 338.402 & 218.477 & 556.879 \\
\hline 2005 & 475.315 & 204.636 & 679.951 \\
\hline 2006 & 480.741 & 210.884 & 691.625 \\
\hline 2007 & 548.168 & 251.900 & 800.068 \\
\hline 2008 & 616.111 & 242.100 & 858.211 \\
\hline 2009 & 581.880 & 233.388 & 815.268 \\
\hline 2010 & 472.742 & 227.089 & 699.831 \\
\hline 2011 & 670.959 & 300.683 & 971.642 \\
\hline 2012 & 762.469 & 351.965 & 1.114 .434 \\
\hline 2013 & 804.348 & 372.960 & 1.177 .308 \\
\hline 2014 & 842.191 & 298.986 & 1.141 .177 \\
\hline 2015 & 911.053 & 371.462 & 1.282 .515 \\
\hline
\end{tabular}

Fuente: Ministerio de Cultura - Dirección Regional de Cultura - Cusco

Elaboración: Observatorio Turístico del Perú 
Estudios realizados en el país coinciden en señalar que el Perú es visto por los extranjeros como un destino Histórico - Cultural, sin embargo, el Perú ofrece un potencial de desarrollo para el turismo de aventura, ecoturismo y otros tipos de turismo, opciones que a nivel mundial también son muy apreciadas.

Aunque sería útil conocer con precisión el tipo de preferencias de los turistas extranjeros, la información disponible permite clasificarlos, entre aquellos que visitan el país por motivos de recreo y aquellos que vienen por negocios. Esta distinción es bastante importante dado que los viajes de recreo se pueden considerar como una demanda final, es decir, son viajes que se emprenden por su propio fin. En cambio, los viajes de negocios son una demanda derivada, es decir, como un insumo necesario para que se produzcan otros bienes. Aquellos que viajan por motivos de recreo suelen gastar menos que los que viajan por motivos de negocio. De otro lado, el número de turistas que visitan el país por motivos de negocios se ha incrementado considerablemente en los últimos años, probablemente debido a las mayores inversiones que vienen realizando las empresas extranjeras en el país.

Según información del Banco Central de Reserva del Perú, así como de las estimaciones del Observatorio Turístico del Perú de la Escuela Profesional de Turismo y Hotelería de la Universidad de San Martín de Porres, a través de su Banco de datos turísticos (Badatur Perú), los turistas extranjeros que visitan el Perú realizan gastos mayores a otros turistas en otros países de Latinoamérica. El gasto Per cápita de los turistas en el país experimentó a partir del año 1990 hasta el 2015, una tasa de crecimiento media anual del 2,54\%. En el año 2015 el gasto Per cápita fue de 1.282 dólares (Tabla 8). Según las pautas dictadas por la Organización Mundial del Turismo, los gastos de transporte no incluyen el pasaje internacional y solo corresponde al traslado hacia los lugares turísticos y la movilidad local. El incremento en el gasto promedio Per cápita entendemos que obedece básicamente a dos factores:

1. El país en virtud a las negociaciones y posterior aprobación del Tratado de Libre Comercio con los Estados Unidos de Norteamérica y otros tratados comerciales celebrados con importantes economías mundiales, recibió muchos visitantes (hombres de negocios), los mismos que según la Organización Mundial del Turismo deben de ser considerados como turistas. Sabido es que el gasto medio de este tipo de visitantes es superior al turista medio que visita el Perú.

2. Otro factor que no se debe de pasar por alto, es el del efecto demostración: Machu Picchu al haber sido postulado y posteriormente elegido entre las nuevas siete maravillas del mundo, provocó en el mercado turístico mundial un incremento superior a la tendencia incremental de su flujo turístico, factor este que incidió también en el incremento del gasto Per cápita. Cabe señalar que el período de permanencia ponderado de los turistas en el país es de 12 días. Los principales rubros de gastos, son en restauración, alojamiento y gastos internos de transporte. 
Tabla 8

Perú: Gasto promedio Per cápita turismo receptor en dólares corrientes

\begin{tabular}{|c|c|c|c|}
\hline Año & Ingresos Turismo Receptor & Cantidad Turistas & Gasto Per cápita en dólares \\
\hline 1990 & 217.000 .000 & 316.871 & 685 \\
\hline 1991 & 225.000 .000 & 232.012 & 970 \\
\hline 1992 & 156.000 .000 & 216.534 & 720 \\
\hline 1993 & 215.000 .000 & 271.901 & 791 \\
\hline 1994 & 331.000 .000 & 386.120 & 857 \\
\hline 1995 & 428.000 .000 & 479.231 & 893 \\
\hline 1996 & 670.000 .000 & 662.736 & 1.011 \\
\hline 1997 & 816.000 .000 & 746.599 & 1.093 \\
\hline 1998 & 845.000 .000 & 819.530 & 1.031 \\
\hline 1999 & 890.000 .000 & 944.000 & 943 \\
\hline 2000 & 911.000 .000 & 793.183 & 1.149 \\
\hline 2001 & 788.000 .000 & 792.466 & 994 \\
\hline 2002 & 801.000 .000 & 859.379 & 932 \\
\hline 2003 & 923.000 .000 & 881.010 & 1.048 \\
\hline 2004 & 1.142 .000 .000 & 1.244 .608 & 918 \\
\hline 2005 & 1.308 .000 .000 & 1.296 .010 & 1.009 \\
\hline 2006 & 1.383 .000 .000 & 1.347 .850 & 1.026 \\
\hline 2007 & 1.854 .000 .000 & 1.540 .107 & 1.204 \\
\hline 2008 & 2.380 .000 .000 & 1.822 .358 & 1.306 \\
\hline 2009 & 2.015 .000 .000 & 1.754 .528 & 1.148 \\
\hline 2010 & 2.242 .472 .508 & 1.949 .976 & 1.150 \\
\hline 2011 & 2.695 .000 .000 & 2.242 .472 & 1.202 \\
\hline 2012 & 3.240 .000 .000 & 2.528 .373 & 1.281 \\
\hline 2013 & 3.514 .000 .000 & 2.742 .526 & 1.281 \\
\hline 2014 & 3.621 .394 .882 & 2.824 .801 & 1.282 \\
\hline 2015 & 4.139.610.050 & 3.229 .025 & 1.282 \\
\hline
\end{tabular}

Fuente: B.C.R.P. BADATUR - OTP

Elaboración: Observatorio Turístico del Perú

\section{El turismo interno peruano}

En los últimos años el Estado dictó diversas medidas orientadas a promover esta actividad. Por ejemplo, se ha dispuesto la acumulación de los feriados en los fines de semana a fin de promover excursiones o viajes cortos de turismo local. El supuesto implícito de esta medida, es que una de las principales restricciones para el desarrollo del turismo nacional es el tiempo de los potenciales turistas. Este supuesto es razonable, aunque pese al crecimiento autosostenido de la economía peruana en los últimos años, el efecto distributivo de la misma es aún incipiente, por lo que la actividad turística interna de largo aliento no se ha desarrollado plenamente. Pese a ello, se han mejorado y/o reparado las principales carreteras del país con lo cual se han acortado las distancias entre los principales lugares de origen (Lima, Arequipa, Trujillo, etc.) y los principales lugares de 
turismo (Ayacucho, Cusco, Trujillo, etc.). El Estado, a diferencia del turismo receptor no se ha propuesto una meta cuantitativa específica en relación al turismo interno nacional.

Si se observa el número de pernoctaciones en los establecimientos de hospedaje, el turismo interno del Perú ascendería a la cifra de 15.479.500 personas que utilizaron algún tipo de establecimiento de hospedaje en el año 2015. Sin embargo, se estima que esta cifra puede estar sobreestimada si la tomamos como referente de personas que residen en el Perú y que realizaron alguna actividad turística en el país; ya que muchos de las personas que hacen uso de los servicios de alojamiento en centros de hospedaje, no lo hacen precisamente por motivos de turismo. PromPerú realizó una encuesta en el año 2014 a los hogares de los extractos económicos A, B y C de las ciudades de Arequipa, Chiclayo, Huancayo, Lima, Piura y Trujillo. Esta encuesta arrojó que del universo de los hogares entrevistados, por lo menos algún miembro había realizado en el año 2014 una actividad turística. Lo cual significó que 1.760 .000 personas realizaron viajes turísticos. Ascendiendo el total de viajes realizados a no más de 4.480.000. Ello, desde luego no implica que de acuerdo a la normatividad de la Organización Mundial del Turismo, se desconozca que personas que realizan viajes por otros motivos dentro del país y que pernoctan por más de un día fuera del lugar de su residencia habitual, deban de dejarse de considerar dentro de las cifras del turismo interno. En consecuencia, de acuerdo a las estimaciones del Ministerio de Comercio Exterior y Turismo (MINCETUR). El total de peruanos o residentes en el país que realizan viajes dentro del Perú sería de 7 millones de personas. Es decir, que a las 1,8 millones de personas cuya única motivación para viajar dentro del país es la de realizar exclusivamente actividades turísticas. De acuerdo a las estimaciones del Observatorio Turístico del Perú se le deberán adicionar 5,2 millones de personas cuya motivación no fue exclusivamente el de viajar por motivos de turismo.

Se puede inferir que esta actividad crecerá en la medida en que se incremente cuantitativa y cualitativamente el empleo y por ende el consumo turístico de la población. Variable, además, dependiente del crecimiento del Ingreso Nacional o PIB.

El motivo principal de los viajes realizados por los turistas nacionales (Perfil del Turista Nacional 2014, PromPerú), es la visita a amigos o parientes. Según el estudio de PromPerú, el 48\% de los turistas entrevistados respondió que su viaje de turismo tenía a su vez como propósito la visita a amigos o parientes, un $45 \%$ de los casos indicó que su propósito fue principalmente turístico, en tanto que un $16 \%$ señaló que viajó adicionalmente por negocios o trabajo. En realidad, estos datos eran los que se esperaban. Las visitas a los amigos o parientes son el motivo principal del turismo nacional en casi todos los países del mundo. Estos turistas usualmente utilizan los días de descanso disponibles para realizar visitas a amigos y parientes, los cuales son de bajo costo, dado que en estos casos los gastos en hospedaje y alimentación se pueden reducir o en todo caso compartir.

En el caso del turismo interno, existe también una clara estacionalidad a lo largo del año, aunque esta es ligeramente diferente a la observada en el turismo receptivo. Existen dos grandes estaciones en la primera mitad del año y dos estaciones medianas en la segunda mitad. La primera de ellas es el mes de enero, que coincide precisamente con el inicio de las vacaciones escolares y de algunas universidades, motivo por el cual muchas familias aprovechan esta ocasión para realizar viajes de turismo. La otra fecha importante es entre marzo y abril, especialmente debido a la Semana Santa, fecha en que las familias viajan masivamente por el 
país. Las otras dos fechas importantes son julio y noviembre. En julio, existen vacaciones escolares y los trabajadores dependientes obtienen pagos adicionales por motivos de gratificaciones de fiestas patrias. En noviembre, existen fiestas regionales que estarían explicando este comportamiento, especialmente en el norte del país.

Los turistas nacionales gastan aproximadamente 500 dólares Per cápita en sus viajes por el país anualmente. El gasto estimado del turista nacional, equivale al 39\% de lo gastado en promedio por el turista extranjero.

\section{El tamaño del mercado turístico y el aporte al PIB}

La información analizada permite ensayar una estimación global del tamaño cuantitativo del mercado turístico en el país. En primer lugar, si se asume que el número de viajeros nacionales asciende a la suma de 7,0 millones de personas (Cifra señalada por el Ministerio de Comercio Exterior y Turismo), en tanto que los turistas extranjeros ascienden a 3,2 millones de personas (Según el Badatur Perú del Observatorio Turístico del Perú). En la actualidad nuestro mercado está conformado por un $69 \%$ de turistas nacionales cuya motivación es la de realizar viajes y un 31\% de turistas extranjeros. En el año 2015, los turistas extranjeros generaron ingresos finales ascendentes a 4.140 millones de dólares. Los turistas nacionales generaron un consumo final de 3.500 millones de dólares, por lo que el tamaño económico del mercado fue de 7.640 millones de dólares, la cifra de ingresos del turismo receptor, representó el 12,0\% de las exportaciones del año 2015; y en términos de aporte al PIB nacional, tanto el turismo interno como el receptivo significaron el 3,75\%.

\section{Los efectos positivos macroeconómicos del turismo en la economía}

El primer efecto que se observa es el incremento del ingreso nacional, vale decir en el producto bruto interno. Según el Badatur Perú del Observatorio Turístico del Perú, la participación del sector turismo en el producto nacional se estima para el año 2015 en 3,75\%; por lo que el PBI del sector turismo para el año 2015 fue de 17.976 millones de nuevos soles; cifra bastante interesante para la economía si consideramos que el mismo es un amplio generador de mano de obra (Tabla 9).

El segundo efecto lo vemos en la participación del turismo receptor en el total de nuestras exportaciones y en el aporte del mismo en el cierre de la brecha de la Balanza Comercial Peruana (Tabla 10).

Un tercer efecto es la generación y contribución de divisas inherentes a la Balanza en Cuenta Corriente, ya que para fines del caso, el turismo receptor se ha convertido en un ente generador de divisas. Siendo la tercera actividad generadora de divisas del país en el 2015, considerando exportaciones tradicionales y no tradicionales (Tabla 11). 
Tabla 9

Perú: P.B.I. del sector turismo

\begin{tabular}{|c|c|c|c|}
\hline Año & $\begin{array}{l}\text { P.B.I. del sector turismo en } \\
\text { miles de nuevos soles } \\
\text { constantes año base } 2007\end{array}$ & $\begin{array}{l}\text { P.B.I. en miles de nuevos } \\
\text { soles constantes }\end{array}$ & $\begin{array}{c}\text { Participación porcentual en el } \\
\text { P.B.I. }\end{array}$ \\
\hline 1994 & 6.371 .540 & 182.044 .000 & $3,50 \%$ \\
\hline 1995 & 6.843 .760 & 195.536 .000 & $3,50 \%$ \\
\hline 1996 & 7.236 .324 & 201.009 .000 & $3,60 \%$ \\
\hline 1997 & 8.133 .064 & 214.028 .000 & $3,80 \%$ \\
\hline 1998 & 8.314 .410 & 213.190 .000 & $3,90 \%$ \\
\hline 1999 & 8.438 .703 & 216.377.000 & $3,90 \%$ \\
\hline 2000 & 8.666 .073 & 222.207.000 & $3,90 \%$ \\
\hline 2001 & 8.943 .200 & 223.580 .000 & $4,00 \%$ \\
\hline 2002 & 8.959 .374 & 235.773 .000 & $3,80 \%$ \\
\hline 2003 & 10.069 .313 & 245.593 .000 & $4,10 \%$ \\
\hline 2004 & 10.310 .800 & 257.770 .000 & $4,00 \%$ \\
\hline 2005 & 10.931 .443 & 273.971 .000 & $3,99 \%$ \\
\hline 2006 & 11.194 .724 & 294.598 .000 & $3,80 \%$ \\
\hline 2007 & 12.372 .119 & 319.693 .000 & $3,87 \%$ \\
\hline 2008 & 15.838 .698 & 348.870 .000 & $4,54 \%$ \\
\hline 2009 & 13.543 .411 & 352.693 .000 & $3,84 \%$ \\
\hline 2010 & 14.280 .375 & 380.810 .000 & $3,75 \%$ \\
\hline 2011 & 15.234 .600 & 406.256 .000 & $3,75 \%$ \\
\hline 2012 & 16.169 .963 & 431.199 .000 & $3,75 \%$ \\
\hline 2013 & 17.129 .513 & 456.787 .000 & $3,75 \%$ \\
\hline 2014 & 17.537 .475 & 467.666 .000 & $3,75 \%$ \\
\hline 2015 & 17.975 .912 & 479.357 .650 & $3,75 \%$ \\
\hline
\end{tabular}

Fuente: BADATUR - OTP, INEI

Elaboración: Observatorio Turístico del Perú 
JOSÉ MANUEL ENRIQUE MARSANO DELGADO

Tabla 10

Balanza Comercial del Perú y los efectos del Turismo Receptor (en millones de dólares)

\begin{tabular}{|c|c|c|c|c|c|c|c|}
\hline Año & Exportaciones & Importaciones & $\begin{array}{c}\text { Saldo } \\
\text { Balanza } \\
\text { Comercial }\end{array}$ & $\begin{array}{l}\text { Ingreso } \\
\text { Turismo } \\
\text { Receptor }\end{array}$ & $\begin{array}{l}\text { Porcentaje en } \\
\text { Participación de } \\
\text { Exportaciones }\end{array}$ & $\begin{array}{c}\text { Saldo Balanza } \\
\text { Turismo } \\
\text { Receptor }\end{array}$ & $\begin{array}{l}\text { Contribución al } \\
\text { Saldo de la } \\
\text { Balanza } \\
\text { Comercial }\end{array}$ \\
\hline 1993 & 3.384 & 4.123 & -739 & 215 & $6 \%$ & -54 & $-7 \%$ \\
\hline 1994 & 4.425 & 5.584 & -1.159 & 331 & $7 \%$ & 65 & $6 \%$ \\
\hline 1995 & 5.492 & 7.750 & -2.258 & 428 & $8 \%$ & 131 & $6 \%$ \\
\hline 1996 & 5.877 & 7.869 & -1.992 & 670 & $11 \%$ & 320 & $16 \%$ \\
\hline 1997 & 6.824 & 8.567 & -1.743 & 816 & $12 \%$ & 382 & $22 \%$ \\
\hline 1998 & 5.757 & 8.262 & -2.505 & 845 & $15 \%$ & 393 & $16 \%$ \\
\hline 1999 & 6.087 & 6.793 & -706 & 890 & $15 \%$ & 447 & $63 \%$ \\
\hline 2000 & 6.951 & 7.407 & -456 & 911 & $13 \%$ & 381 & $84 \%$ \\
\hline 2001 & 7.007 & 7.273 & -266 & 788 & $11 \%$ & 196 & $74 \%$ \\
\hline 2002 & 7.647 & 7.440 & 207 & 801 & $10 \%$ & 185 & $-89 \%$ \\
\hline 2003 & 8.986 & 8.285 & 701 & 923 & $10 \%$ & 303 & $-43 \%$ \\
\hline 2004 & 12.547 & 9.818 & 2.729 & 1.034 & $8 \%$ & 393 & $-14 \%$ \\
\hline 2005 & 17.247 & 12.084 & 5.163 & 1.241 & $7 \%$ & 561 & $-11 \%$ \\
\hline 2006 & 23.800 & 14.866 & 8.934 & 1.383 & $6 \%$ & 627 & $-7 \%$ \\
\hline 2007 & 27.955 & 19.599 & 8.356 & 1.854 & $7 \%$ & 812 & $-10 \%$ \\
\hline 2008 & 31.594 & 28.432 & 3.162 & 2.380 & $8 \%$ & 1.105 & $-35 \%$ \\
\hline 2009 & 26.885 & 21.011 & 5.874 & 2.015 & $7 \%$ & 934 & $-16 \%$ \\
\hline 2010 & 35.565 & 28.815 & 6.750 & 2.242 & $6 \%$ & 1.019 & $-15 \%$ \\
\hline 2011 & 46.269 & 36.967 & 9.302 & 2.695 & $6 \%$ & 1.281 & $-14 \%$ \\
\hline 2012 & 45.639 & 41.113 & 4.526 & 3.240 & $7 \%$ & 1.605 & $-35 \%$ \\
\hline 2013 & 41.826 & 42.191 & -365 & 3.514 & $8 \%$ & 1.623 & $445 \%$ \\
\hline 2014 & 38.253 & 40.807 & -2.554 & 3.621 & $9 \%$ & 1.778 & $70 \%$ \\
\hline 2015 & 34.157 & 37.021 & -2.864 & 4.140 & $12 \%$ & 1.993 & $70 \%$ \\
\hline
\end{tabular}

Fuente: B.C.R.P. BADATUR del OTP

Elaboración: Observatorio Turístico del Perú 
Tabla 11

Principales productos y servicios generadores de divisas (en millones de dólares)

\begin{tabular}{rcccccccr}
\hline Año & Mineros & $\begin{array}{c}\text { Agrícolas y } \\
\text { Agopecuarios }\end{array}$ & Pesqueros & $\begin{array}{c}\text { Petróleo } \\
\text { Derivados }\end{array}$ & Textiles & Turismo & $\begin{array}{c}\text { Sidero- } \\
\text { Metalúrgicos y } \\
\text { Joyería }\end{array}$ & Químicos \\
\hline 2006 & 14.851 & 1.785 & 1.763 & 1.713 & 1.469 & 1.383 & 829 & 601 \\
2007 & 17.493 & 1.963 & 1.954 & 2.248 & 1.730 & 1.854 & 907 & 803 \\
2008 & 18.656 & 2.597 & 2.413 & 2.663 & 2.018 & 2.380 & 908 & 1.041 \\
2009 & 16.508 & 2.456 & 2.200 & 1.894 & 1.492 & 2.015 & 560 & 837 \\
2010 & 21.974 & 3.165 & 2.526 & 3.088 & 1.558 & 2.242 & 918 & 1.223 \\
2011 & 27.849 & 4.503 & 3.146 & 4.704 & 1.986 & 2.695 & 1.128 & 1.645 \\
2012 & 26.637 & 4.122 & 3.302 & 4.959 & 2.157 & 3.240 & 1.253 & 1.624 \\
2013 & 23.750 & 4.181 & 2.724 & 5.148 & 1.919 & 3.514 & 1.264 & 1.495 \\
2014 & 18.950 & 4.976 & 2.877 & 4.559 & 1.795 & 3.621 & 1.145 & 1.509 \\
2015 & 19.529 & 5.054 & 2.369 & 2.301 & 1.324 & 4.140 & 1.075 & 1.393 \\
\hline
\end{tabular}

Fuente: BCRP, BADATUR - OTP

Elaboración: Observatorio Turístico del Perú

\section{Conclusiones}

1. En una economía globalizada, donde los medios de comunicación juegan un papel importante en la formación de la opinión pública, con una rapidez inusitada, es esencial cuidar tanto la imagen interna como externa del país.

2. El Perú ya experimentó el impacto de una convulsión social, que estuvo a punto de quebrar la totalidad de la industria turística, haciéndonos perder muchos mercados y permitiendo que al amparo de ello, aparecieran nuevos países ofertantes, atrasándonos en lo referente a la generación de infraestructura de planta en comparación con otros países que tienen similar oferta turística que el Perú.

3. El Estado debe de tener mucho cuidado en lo referente a la estabilidad de las políticas económicas en general y en particular a los incentivos técnicos hacia este sector, no solo por ser un rubro generador de divisas, sino por la capacidad generadora de mano de obra que el mismo implica.

4. Nuestra oferta turística en un $92 \%$ es de naturaleza histórico - cultural. Sin embargo, no es menos cierto que el país gozó de ventajas comparativas en este tipo de turismo; pero hoy en día muchos países con similares características al tipo de turismo peruano han ampliado su abanico de oferta turística, combinando este tipo de turismo, con otros como el de aventura, el recreacional, el ecoturismo y otros. Por lo tanto, el Perú debe seguir estos ejemplos ya que en el mediano plazo se puede encontrar con ingratas sorpresas. 
5. Se debe tener presente, que en una economía moderna, las ventajas comparativas en lo relacionado con el turismo, no siempre se han obtenido por herencia. Con ello, nos referimos al turismo recreacional, al de aventura y muchos otros, que poniendo al servicio de la industria turística la aplicación de tecnologías de punta, existen países que han logrado convertir regiones de sus territorios en verdaderos paraísos turísticos, consiguiendo ventajas competitivas difíciles de superar.

\section{Bibliografía recomendada}

BADATUR PERU. Recuperado de www.observatorioturisticodelperu.com

B.C.R.P. Recuperado de www.bcrp.gob.pe

Barros de Castro, A. \& Lessa, C. (1995). Introducción a la economía. Un enfoque estructuralista. México: Siglo Veintiuno

Editores. Marsano, J. M. E. (2003). Economía del Turismo. Lima: Universidad de San Martín de Porres.

Monitor (1995). Turismo en el Perú. Lima: Comisión de Promoción del Perú.

PromPerú (2011 1a). Perfil del Turista Extranjero 2010. Lima: Comisión de Promoción del Perú.

PromPerú (2014 1b). Perfil del Turista Nacional 2010. Lima: Comisión de promoción del Perú. 